\title{
Occurrences of Sinolagomys (Lagomorpha) from the Valley of Lakes (Mongolia)
}

\author{
Margarita Erbajeva $^{1}$ (D) - Bayarmaa Baatarjav ${ }^{2}$. \\ Gudrun Daxner-Höck ${ }^{3} \cdot$ Lawrence J. Flynn $^{4}$
}

Received: 23 July 2016 /Revised: 15 September 2016 / Accepted: 9 November 2016 / Published online: 25 January 2017

(C) The Author(s) 2017. This article is published with open access at Springerlink.com

\begin{abstract}
The genus Sinolagomys is an early representative of the family Ochotonidae, appearing first in the late early Oligocene of Central Asia. It is known in China from Shargaltein Tal, Taben Buluk, Ulan Tatal, and northern Junggaria, and a few specimens from Tatal Gol, Mongolia have been published. For most occurrences, the genus is not represented by many specimens. Extensive studies in the Valley of Lakes, Central Mongolia, have produced a large number of sinolagomyin fossils spanning at least 10 million years and belonging to five species: Sinolagomys kansuensis, Sinolagomys major, Sinolagomys gracilis, Sinolagomys ulungurensis, and Sinolagomys badamae sp. nov. Descriptions
\end{abstract}

This article is a contribution to the special issue "The Valley of Lakes in Mongolia, a key area of Cenozoic mammal evolution and stratigraphy"

This article is registered in Zoobank under: urn:lsid:zoobank.org: act:F0708E7BEBF7-4571-A756-965ADE5C87CD

Margarita Erbajeva

erbajeva@gin.bscnet.ru

Bayarmaa Baatarjav

bayaraa_bio85@yahoo.com

Gudrun Daxner-Höck

gudrun.hoeck@sbg.at

Lawrence J. Flynn

ljflynn@fas.harvard.edu

1 Geological Institute, Siberian Branch, Russian Academy of Sciences, Sahianova Str., 6a, Ulan-Ude 670047, Russia

2 Institute of Palaeontology and Geology, Mongolian Academy of Sciences, Danzan Str., Post 46/650, Ulaanbaatar, Mongolia

3 Rupertusstr. 16, 5201 Seekirchen, Austria

4 Department of Human Evolutionary Biology, Harvard University, 11 Divinity Avenue, Cambridge, MA 02138, USA of these are given, as well as definition of the new species. Sinolagomyins flourished during the late Oligocene and early Miocene and came to occupy vast territories from China through Mongolia and Kazakhstan. The evolution of this ochotonid group is characterized by increasing taxonomic diversity and progressive development of rootless cheek teeth.

Keywords Ochotonidae $\cdot$ Sinolagomys $\cdot$ Dentition

Oligocene $\cdot$ Valley of Lakes $\cdot$ Mongolia

\section{Introduction}

The Order Lagomorpha, originating in Central Asia likely during the Paleocene Epoch (Asher et al. 2005), was represented by a number of early stem group lagomorphs such as genera Khaychina, Eomylus, Amar, Zagmys, Mimotona, Eurymylus, Gomphos, placed variously in the higher taxa Anagalida and Mimotonidae. The earliest lagomorphs were small sized, first class herbivore consumers in early Cenozoic ecology. The Eocene climate in Asia changed, drying as it became continental due to the influence of the Antarctic ice accumulation (Wolfe 1971). Globally, the climate continued to remain warm and humid in some areas (Berggren and Prothero 1992), but tropical forest gradually declined, the most archaic stem group genera disappeared, and a number of lagomorphs died out at the transition from the Eocene to the Oligocene. Stem group Lagomorpha were replaced by the early genera of a more advanced grade (Lushilagus, Shamolagus, Strenulagus, Gobiolagus) and by the first paleolagid, the genus Desmatolagus.

The first investigation of lagomorphs from Central Asia, specifically the Taatsin Gol area, was conducted by the Central Asiatic Expedition of the American Museum of Natural History (AMNH) (Matthew and Granger 1923). Matthew and Granger were the first to describe new taxa of 
Desmatolagus from the Hsanda Gol Formation. However, they did not mention the existence of a different form (later known as Sinolagomys) among a thousand desmatolagin fossils. The genus Sinolagomys stored at the AMNH (New York) is represented by a single jaw fragment with $\mathrm{p} 3-\mathrm{m} 1$ under collection number "AMNH FM: 56648."

Later, based on material collected by the joint SovietMongolian Paleontological expeditions, Gureev (1960) described from the Tatal Gol locality ten different lagomorph taxa, mostly desmatolagins, among which three fragments of ochotonid lower jaw with variable structure of $\mathrm{p} 3$ were discovered. One of them was described as new, under the species name Sinolagomys tatalgolicus.

The genus Sinolagomys had been recognised for the first time by Bohlin (1937) from the Oligocene localities of Shargaltein Tal, in Northern China. Early studies of Sinolagomys led to the recognition of three species: Sinolagomys kansuensis, Sinolagomys major, and Sinolagomys minor, the latter renamed by Bohlin as Sinolagomys gracilis (Bohlin 1942).

On the basis of the Tatal Gol specimens and revision of other Chinese ochotonid species, Gureev was of the opinion that Sinolagomys, although unusual, belongs to family Ochotonidae (=Lagomyidae), at that time including surviving species of the Holarctic genus Ochotona. The genus Sinolagomys differs from typical Ochotona in the simple structure of the main diagnostic teeth (p3 and P4-M2) and by retaining reduced cheek teeth roots.

These data allowed Gureev to refer Sinolagomys to an independent group for which he created the new subfamily Sinolagomyinae Gureev 1960. Later some specimens of S. kansuensis were discovered in Oligocene faunas of China (Huang 1987; Wang and Qiu 2000). Also, new species were defined for Miocene faunas of the region; Sinolagomys pachygnathus Li et Qiu and Sinolagomys ulungurensis Tong (Li and Qiu 1980; Tong 1989). This demonstrated that the genus Sinolagomys survived the Oligocene-Miocene transition.

During the last decades comprehensive investigations of the joint Austrian-Mongolian Expeditions were conducted in the Valley of Lakes, Central Mongolia. Field work resulted in the collection of a great number of mammal fossils including lagomorphs in the region (Daxner-Höck et al. 2017, this issue), in particular an impressive number of ochotonid specimens of the genus Sinolagomys now stored in the NHMW (Vienna, Austria) and in the MPC/L (Ulaabaatar, Mongolia). Only fossils of the NHMW collection are considered in this study.

The present paper describes for the first time abundant fossil sinolagomyins collected from more than 50 localities of the Valley of Lakes, spanning in age the early late Oligocene to early Miocene. It is believed that the first archaic ochotonids represented by the genus Sinolagomys appeared by the latest early Oligocene. However, these are poorly preserved and uncommon, in contrast to other late Oligocene lagomorphs. Later, the genus flourished, with significant diversification and increasing abundance. Five Oligocene taxa are known in this region in addition to S. tatalgolicus. Among the ochotonid remains, there are several lower jaw fragments that differ from each other by structure of the valuable diagnostic tooth (p3) and can be recognised as different morphospecies, given the scarce materials. In the future with more material, these may be referred to independent taxa.

The genus continued to flourish through the late Oligoceneearly Miocene demonstrating an exceptional transition of the Paleogene-Neogene boundary. The stratigraphic ranges of Sinolagomys species from Mongolia are shown in Table 1.

By then ochotonids (Ochotonidae) had dispersed over the huge territory of Asia from China and Mongolia in the east through Kazakhstan and beyond in the west $(\mathrm{Li}$ and Qiu 1980; Huang 1987; Tong 1989; Erbajeva 1988, 1994, 2007; Lopatin 1998; Wang and Qiu 2000; Meng et al. 2006, 2013; Bendukidze et al. 2009; Erbajeva and Daxner-Höck 2014; Erbajeva et al. 2016). Sinolagomyinae are a characteristic element of small mammalian assemblages of Central Mongolia (Valley of Lakes). They are a species-rich group playing an important role for palaeoenvironmental reconstruction in the region and they facilitate interregional correlations.

At the present time, the genus includes S. kansuensis Bohlin 1937 (type species), S. major Bohlin 1937, S. gracilis (Bohlin 1942), S. tatalgolicus Gureev 1960, S. ulungurensis Tong 1989, S. pachygnathus Li and Qiu 1980, and Sinolagomys badamae sp. nov.

\section{Material and methods}

New material is stored in the collection of the Natural History Museum of Vienna, Vienna, Austria. A second rich lagomorph collection from the same fossil sites is housed in the Mongolian Paleontological Center, Academy of Sciences, Ulaanbaatar. Fossils were collected during eight field seasons since 1995 by teams of the Joint Austrian-Mongolian Projects (FWF: P-10505-GEO, P-15724-N06, and P-23061-N19) through screen washing and as surface finds on exposed deposits.

Type specimens and fossils of the genus Sinolagomys from the localities Shargaltein Tal, Taben Buluk, and Ulan Tatal were examined in the collections of the Institute of the Vertebrate Paleontology and Paleoanthropology, Chinese Academy of Sciences, Beijing, China. Type specimens of $S$. tatalgolicus from Tatal Gol and Sinolagomys sp. from Hsanda Gol were studied in the collections of the Paleontological Institute, Moscow, and American Museum of Natural History, New York, respectively. 
Table 1 Stratigraphic chart including the geologic time scale (Gradstein et al. 2012), Mongolian biozones C1-D (Höck et al. 1999), the Europe MN/ MP zones after Steininger (1999) and Luterbacher et al. (2004), the lower boundary of the Xiejian Chinese mammal age after Meng et al. (2013), the stratigraphic ranges of the genus Sinolagomys in Mongolia. Sporadic earlier occurrences of $S$. major and $S$. kansuensis are not considered in this chart

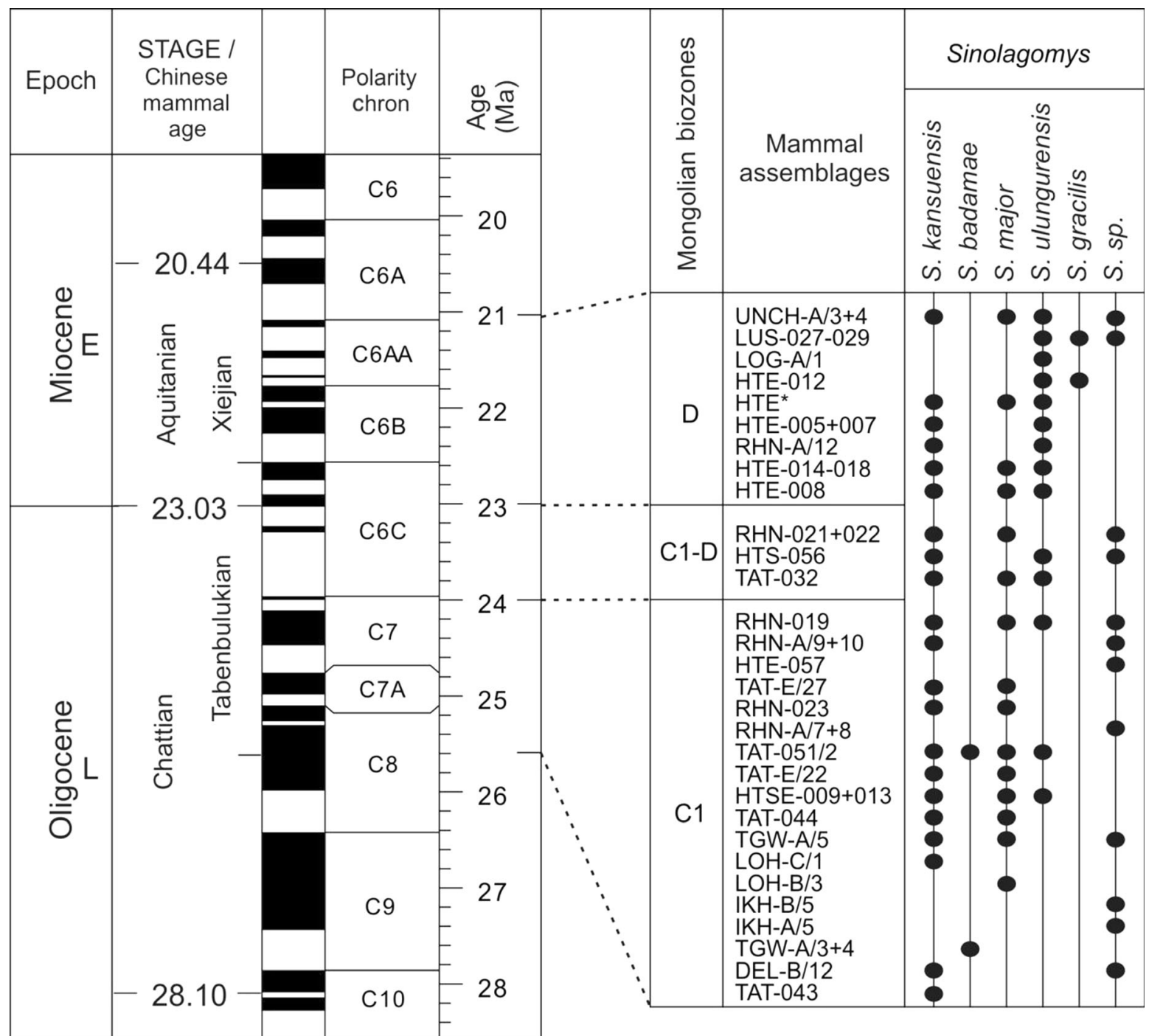

The measurements (mm) were taken using MBS-10 microscope. The terminology of dental elements follows Lopez Martinez (1989) and in part Erbajeva (1988). The classification of Lagomorpha follows Gureev (1964), with the genus Sinolagomys placed in the subfamily Sinolagomyinae of the family Ochotonidae.

Abbreviations: NHMW—-Museum of Natural History Vienna, Geological-Paleontological Department, Vienna, Austria AMNH-American Museum of Natural History, New York, USA

IVPP-Institute of Vertebrate Paleontology and Paleo-anthropology, Chinese Academy of Sciences, China MPC/L—Mongolian Paleontological Collection/Lagomorphacollections of the Institute of Palaeontology and Geology, Mongolian Academy of Sciences, Ulaanbaatar, Mongolia
PIN—Paleontological Institute Russian Academy of Sciences, Moscow, Russia

Teeth: P, p-premolar; M, m-molar. Upper case letters indicate upper teeth; lower case for lower teeth. $L-$ length and $W$-width of teeth, ant-anteroloph, hyphypostria, tr - trigonid, tal - talonid, $n$ - number of specimen, $m$-mean, Min and Max — range of quantity, $s$ - standard deviation

\section{Systematic Palaeontology}

Order Lagomorpha Brandt, 1855

Family Ochotonidae Thomas, 1897

Subfamily Sinolagomyinae Gureev, 1960

Genus Sinolagomys Bohlin, 1937 
Type locality: Shargaltein Tal, Gansu (China), late Oligocene

Stratigraphic range: Late early Oligocene to early Miocene Diagnosis: (after Bohlin 1937: 32; 1942: 95 with some corrections). Teeth small to medium-sized, moderately high crowned or hypsodont; no roots on upper teeth, rudimentary roots in lower teeth. P2: small; P3: paraflexus moderately deep; anteroloph short, not exceeding $1 / 3$ of tooth width; internal hypostria short, with little cement; depth of hypostria on P4-M2 reaches half of tooth width or slightly more; M3: absent. Cross-section of $\mathrm{p} 3$ varies from rectangular to square; anterior margin flat or with vertical groove, shallow without cement varying to deep and filled with cement; antero-external fold filled with cement; trigonid of p4-m2 wider than talonid.

Type species: Sinolagomys kansuensis Bohlin, 1937; Holotype, P3-M2, Sh. 429. IVPP, Beijing, China

Referred species with type localities and geological age range: S. kansuensis Bohlin, 1937; Shargaltein-Tal (China); late early Oligocene-early Miocene (type species)

S. major Bohlin, 1937; Shargaltein-Tal (China); late early Oligocene-early Miocene

S. gracilis (Bohlin 1942); Shargaltein-Tal (China); late Oligocene-early Miocene

S. tatalgolicus Gureev, 1960; Tatal-Gol (Mongolia); late Oligocene

S. pachygnathus Li and Qiu, 1980; Xiejia (China); early Miocene

S. ulungurensis Tong, 1989; Chibaerwoyi (China); late Oligocene-early Miocene

S. badamae sp. nov., Toglorhoi (Mongolia); late Oligocene

Sinolagomys major Bohlin, 1937 (Figures 1 and 2; Tables 2 and 3)

1937 Sinolagomys major-Bohlin: 34-35, text-figs 58-61; Taf. 1. Fig. 18

1942 Sinolagomys major -Bohlin: 86-104, text-figs 24, 25A, ?C, 26A-C; 29; 31; 32 A, B

1987 Sinolagomys major-Huang: 272-275, text-fig. 12 1988 Sinolagomys major -Erbajeva: 50-51

2000 Sinolagomys cf. S. major - Wang and Qiu, pl. II, figs. 9-12

2014 Sinolagomys-Erbajeva and Daxner-Höck: 233237, text-figs. 13-15

Type locality: Shargaltein Tal, Gansu (China), late Oligocene Type species: Sinolagomys major Bohlin, 1937

Holotype: P3-M1, Sh. 830. IVPP, Beijing, China

Stratigraphic range: Late early Oligocene to early Miocene
Emended diagnosis: Large-sized; hypsodont teeth; rootless; upper cheek tooth crown slightly curved transversely; two thin plates (metasyle) follow from the occlusal surface of tooth towards root down the labial border of crown. On upper teeth (P4, M1, M2) depth of hypostria is variable. Lower p3 of rectangular shape, antero-external fold filled with cement; lower cheek teeth with trigonid wider than talonid.

Referred material: Fossils of Sinolagomys major are rather abundant. Studied materials are skull fragments, mandibles and isolated teeth sampled from the localities:

Early Oligocene (biozone B): Ikh Argalatyn Nuruu: IKH-A/1: M1 (NHMW 2016/0165/0001)

Late Oligocene (biozone C1):

Tatal Gol: TAT-044: 1 p3, 1 P4 (NHMW 2013/0105/ 0001-0002); TAT-052/1: 1 P4-M3, 1 P3 (NHMW 2013/0363/0001-0002); TAT-052/2: 1 P4 (NHMW 2013/0386/0001); TAT-E/22: 2 P4, 1 M2 (NHMW 2013/0278/0001-0003)

Toglorhoi: TGW-A/5: 1 M1 (NHMW 2016/0163/0001); TGS-A/O: 1 P4 (NHMW 2011/0194/0001)

Loh: LOH-B/3: 1 P4 (NHMW 2013/0364/0001)

Huch Teeg: RHN-A/7: 1 P4 (NHMW 2013/0366/0001); RHN-A/9: 1 P4 (NHMW 2016/0162/0001); RHN-019: 1 P3, 2 P4, 1 M1, 1 M2 (NHMW 2013/0367/0001-0005); HTSE-009:1 p4, 1 p3-m1 (NHMW 2013/0365/0001-0002); RHN-021: 2 P3M2, 3 P3, 1 P4, 2 M1, 1 p3-m3, 1 m1-m3, 1 p3, 1 m1 (NHMW 2013/0387/0001-12); RHN-022: 1 P3-M2, 1 p3-m3 (NHMW 2013/0325/0001); HTSE-056: 1 P3 (NHMW 2013/0385/0001) Early Miocene (biozone D):

Hotuliin Teeg: HTE-016-017: $1 \mathrm{~m} 1,1 \mathrm{~m} 2$ (NHMW 2013/0388/0001-0002); HTE-008: 1 P3-M3, 4 P3-M2, 1 P3M1, 11 P3, 14 P4, 11 M1, 7 M2, 2 p3-m3, 4 p3-m2, 2 p3-p4, 1 p4-m3, 3 p4-m2, 2 p4-m1, 1 m1-m3, 2 m2-m3, 7 p3, 6 p4, 9 m1, 1 m2 (NHMW 2013/0389/0001-0089); HTE *: 1 P3-M2, 1 P4 (NHMW 2013/0195/0001-0002); HTE-009: 3 P4, 3 M1 (NHMW 2016/0164/0001-0006)

Huch Teeg: RHN-020: 3 P4 (NHMW 2013/0390/ 0001-0003)

Uncheltseg: UNCH-A/4: 1 P4 (NHMW 2014/0391/0001); UNCH-O: 1 P4 (NHMW 2011/0193/0002)

\section{Description}

The largest sinolagomyin, with hypsodont teeth; a marked ridge on the maxillary bone runs from the boundary of P3 and P4 alveoli towards zygomatic root; anterior and posterior to this ridge, there are depressions on the maxilla, relatively deep anterior and shallow posterior.

On upper teeth (P3, P4, M1, M2), two thin plates (metastyle) follow down from the occlusal surface towards root along height of tooth crown. It is safe to assume that such 
thin plates are rudiments of external roots that existed in the teeth of sinolagomyin ancestors.

Lingual borders of upper teeth (P4, M1, M2) slightly rounded; protocone larger than hypocone; enamel band is well developed across perimeter of tooth, but its thickness is variable.

P2: not known in our materials. However, Bohlin (1942, p. 92, T.b. 586a, fig. 27c) illustrates P2 with one anterior fold.

P3: oval-trapezoidal outline, tooth slightly longer on lingual part than labially, its anterior width significantly less than posterior width; paraflexus moderately deep; anteroloph extends to half of tooth width; internal hypostria short with little cement (Figs. 1a and 2a)

P4: in contrast to P3 tooth much wider anteriorly than posteriorly. No basic changes in $\mathrm{P} 4$ structure occur in Sinolagomys major from the late early Oligocene to early Miocene; all known specimens of $\mathrm{P} 4$ with the distinctive, characteristic significantly greater anterior width. Hypostria relatively short, extending across half of tooth width, with little cement; the type specimen from Shargaltein Tal (P3-M1, Sh. 830, fig. 58, Bohlin 1937, p. 34) is characteristic, with rather short hypostria (Figs. $1 \mathrm{~b}$ and $2 \mathrm{c}$ ).

M1: smaller than preceding tooth, anterior width of tooth slightly broader than, or equal to posterior width; enamel band well developed on the anterior and lingual margins of tooth; hypostria relatively deep, extends across half of tooth width or slightly more, filled with cement (Figs. 1a and 2d)

M2: small, anterior width of tooth exceeds posterior one; internal side of tooth inclined much towards postero-internal corner; hypostria deep, extends almost external to border of tooth (Fig. 2a)

M3: small, rounded, but usually lacking. The unique P3-M3 from the site HTE-008 (NHMW 2011/0389/0089) contains this tooth (Fig. 2a, Table 2).

Mandible relatively high, slightly robust (depth below $\mathrm{p} 4$ $7.0-7.3 \mathrm{~mm}$; width $5 \mathrm{~mm}$ ), root of lower incisor extending to below the talonid of $\mathrm{m} 2$ forms marked convexity on both labial and lingual surface of mandible. Anterior foramen mentale located in front of $\mathrm{p} 3$ on the level of mid-height of mandible, the other two mental foramina are under $\mathrm{p} 4$. Enamel band well developed in all borders of lower teeth (p4-m2) except the anterior margin.

p3: rectangular shape with rounded margins; anterior border flat or with shallow depression with little or no cement; antero-external fold filled with little cement (Fig. 2b)

p4-m2: trigonids wider than talonids (Table 3) having oval shape, enamel band is thick on the posterior margin of conids.

m3: small oval conid, however in one specimen it is tiny ( $\mathrm{m} 2-$ m3, NHMW 2013/0194/0004). Similar small m3 was found in lower jaw of Sinolagomys major from Ulan Tatal (Huang
1987, fig. 12) and in one mandible of Eurolagus from La Grive, France.

Discussion: S. major from the Valley of Lakes resembles the type specimen from the locality Shargaltein Tal (Bohlin 1937, fig. 58; Sh. 830) in size and general structure of teeth, but differs by deeper hypostria of upper teeth; however, the ratio of the trigonid and talonid width in p4-m2 (Sh. 270, paratype) is similar.

A large ochotonid cited originally as Lagomys by Teilhard de Chardin (1926, fig. 14 A, p. 26), from the locality SaintJacques, Ordos, China, doubtlessly represents the genus Sinolagomys. Later, this specimen (P4 with relatively deep hypostria) was recognised by de Muizon (1977) as Sinolagomys cf. major Bohlin 1937.

S. major is known from the locality UlanTatal, China (Huang 1987). It is close to the population from the Valley of Lakes in size, the morphological structure of teeth, and lack of roots. This species is mentioned as well in the late Oligocene fauna of the northern Junggar basin, China (Meng et al. 2006).

Ochotonolagus argyropuloi Gureev 1960, large-sized ochotonid from Tatal Gol, Mongolia (Gureev 1960, Fig. 3a, b) resembles Sinolagomys major by the structure of the lower jaw general features of the occlusal surface of teeth (trigonids slightly wider than talonids), however it differs from the studied Mongolian form by retaining an oval shape $\mathrm{m} 3$ and by slightly smaller size. Lower cheek tooth length, p4$\mathrm{m} 3$, is $6.7 \mathrm{~mm}$ in contrast to $7.3 \mathrm{~mm}$ in S. major from Loc. HTE-008. Lack of $\mathrm{p} 3$ in $O$. argyropuloi prevents definitive referral to S. major.
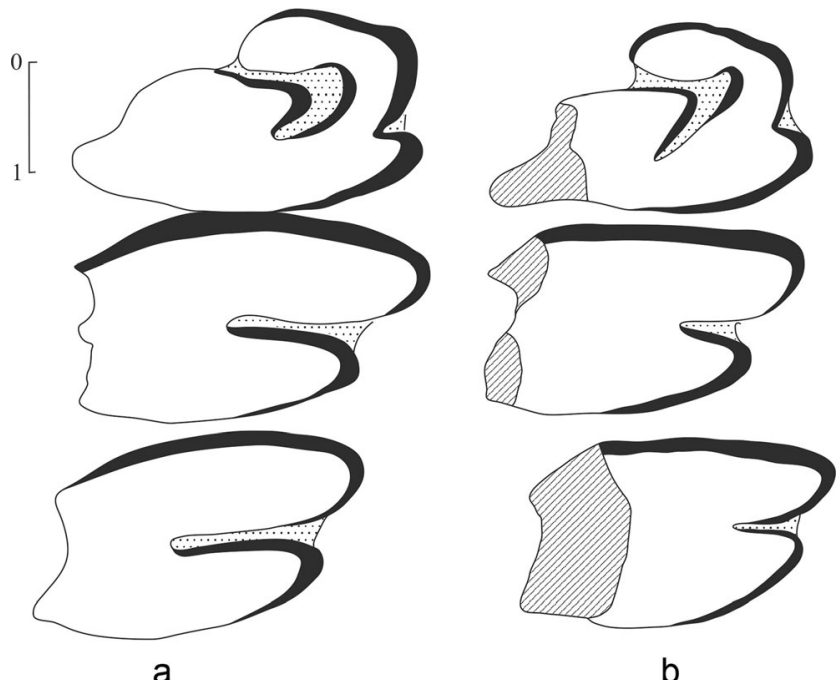

b

Fig. 1 Sinolagomys major Bohlin, 1937 from the Valley of Lakes in Mongolia. a Right P3-M1 (NHMW 2013/0389/0088) from Hotuliin Teeg (HTE-008), early Miocene (biozone D). b Right P3-M1 (type, Sh. 830, IVPP, Beijing) from Shargaltein Tal, China, Late Oligocene 

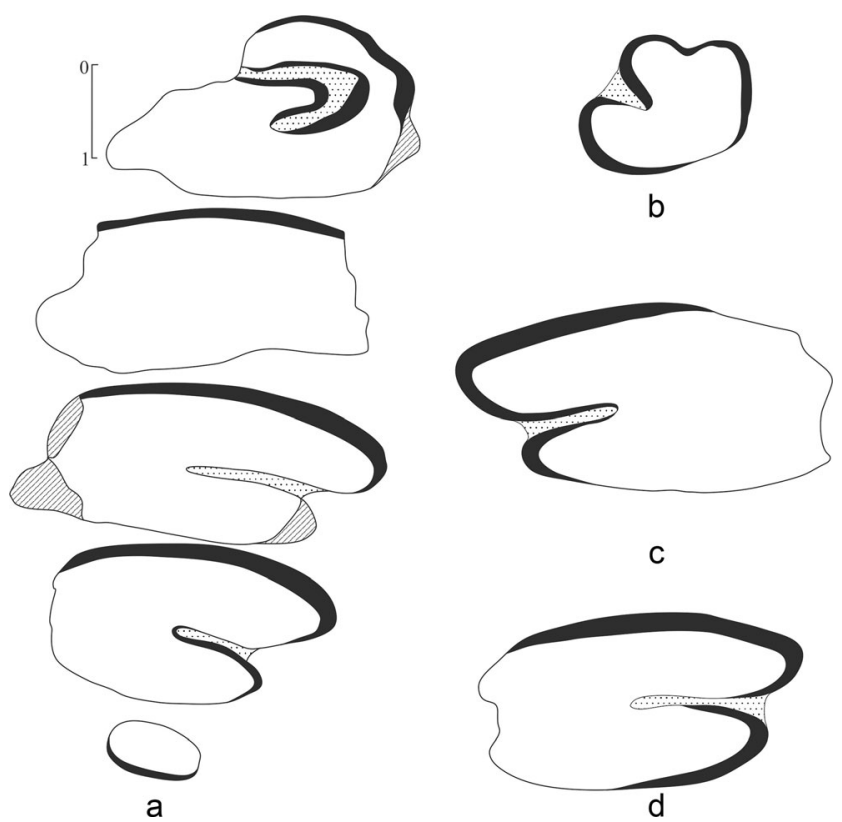

Fig. 2 Sinolagomys major Bohlin, 1937 from the Valley of Lakes in Mongolia. a Right P3-M3 (NHMW 2013/0389/0089, from Hotuliin Teeg (HTE-008), early Miocene (biozone D). b Left p3 (NHMW 2013/0387/0008) from Huch Teeg (RHN-021), late Oligocene (biozone C1). c Left P4 (NHMW 2013/0386/0001) from Tatal Gol (TAT-52/2), late Oligocene (biozone C1). d Right M1 (NHMW 2013/0367/0005) from Huch Teeg (RHN-019), late Oligocene (biozone $\mathrm{C} 1$ )

Table 2 Upper tooth measurements (in $\mathrm{mm}$ ) of Sinolagomys major Bohlin, 1937

\begin{tabular}{lllllll}
\hline $\mathrm{Nr}$ & Specimens & $n$ & $m$ & Min & Max & $s$ \\
\hline 1 & P3-M3 L coronar & 1 & 8 & & & \\
2 & P3-M2 & 5 & 7.25 & 7 & 7.5 & 0.18 \\
3 & P3-M1 & 6 & 5.58 & 5.4 & 5.8 & 0.157 \\
4 & P3-P4 & 5 & 3.63 & 3.4 & 3.75 & 0.140 \\
5 & P3 & 13 & 1.76 & 1.6 & 2 & 0.141 \\
6 & P3 W & 13 & 2.88 & 2.5 & 3.1 & 0.168 \\
7 & P3 W ant & 11 & 1.61 & 1.5 & 2 & 0.164 \\
8 & P4 & 22 & 1.79 & 1.65 & 2 & 0.104 \\
9 & P4 W & 22 & 3.42 & 3 & 4 & 0.275 \\
10 & P4 W hyp & 21 & 1.77 & 1.5 & 2.1 & 0.182 \\
11 & M1 & 11 & 1.74 & 1.5 & 2.15 & 0.161 \\
12 & M1 W & 9 & 3.2 & 3 & 3.5 & 0.154 \\
13 & M1 W hyp & 10 & 1.93 & 1.65 & 2.5 & 0.242 \\
14 & M2 & 8 & 1.58 & 1.45 & 1.65 & 0.065 \\
15 & M2 W & 8 & 2.8 & 2.4 & 3.2 & 0.271 \\
16 & M2 W hyp & 8 & 1.57 & 1.25 & 1.8 & 0.187 \\
17 & M3 & 1 & 0.55 & & & \\
18 & M3 W & 1 & 1 & & & \\
\hline
\end{tabular}

Table 3 Lower tooth measurements (in $\mathrm{mm}$ ) of Sinolagomys major Bohlin, 1937

\begin{tabular}{lllllll}
\hline $\mathrm{Nr}$ & Specimens & $n$ & $m$ & Min & Max & $s$ \\
\hline 1 & p4-m2 & 5 & 6.41 & 6.2 & 6.7 & 0.201 \\
2 & p3 L & 6 & 1.53 & 1.45 & 1.6 & 0.061 \\
3 & p3 W & 6 & 1.99 & 1.85 & 2.25 & 0.156 \\
4 & p4 & 20 & 2.2 & 1.75 & 2.55 & 0.234 \\
5 & p4 L tr & 20 & 1.07 & 0.95 & 1.3 & 0.095 \\
6 & p4 W tr & 20 & 2.29 & 1.5 & 2.8 & 0.336 \\
7 & p4 L tal & 20 & 1.1 & 0.85 & 1.5 & 0.191 \\
8 & p4 W tal & 19 & 1.8 & 1.55 & 2.15 & 0.191 \\
9 & m1 & 18 & 2.19 & 1.75 & 2.6 & 0.250 \\
10 & m1 L tr & 18 & 1.11 & 0.9 & 1.35 & 0.132 \\
11 & m1 W tr & 18 & 2.41 & 2 & 3 & 0.319 \\
12 & m1 L tal & 18 & 1.04 & 0.8 & 1.25 & 0.143 \\
13 & m1 W tal & 17 & 1.74 & 1.5 & 2 & 0.175 \\
14 & m2 & 15 & 2.37 & 1.6 & 2.8 & 0.339 \\
15 & m2 L tr & 15 & 1.1 & 0.8 & 1.35 & 0.139 \\
16 & m2 W tr & 14 & 2.46 & 1.8 & 3 & 0.348 \\
17 & m2 L tal & 15 & 1.17 & 0.8 & 1.4 & 0.190 \\
18 & m2 W tal & 14 & 1.79 & 1.2 & 2.1 & 0.255 \\
19 & m3 L & 7 & 0.77 & 0.4 & 1 & 0.281 \\
20 & m3 W & 7 & 0.97 & 0.45 & 1.25 & 0.328 \\
\hline & & & & & & \\
\hline
\end{tabular}

Sinolagomys kansuensis Bohlin, 1937 (Figures 3 and 4; Tables 4 and 5)

1937 Sinolagomys kansuensis sp. nov.—Bohlin: 31-34, figs. $50-57$

1942 Sinolagomys kansuensis—Bohlin: 96-99, pl. 1, figs. 18-31, text-figs. 24, 26

1987 Sinolagomys kansuensis - Huang: 272-274, text-fig. 11 1988 Sinolagomys kansuensis - Erbajeva: 49-50, text-fig. 10 2000 Sinolagomys kansuensis - Wang and Qiu: 262-259, pl. II, figs. 1-8

2009 Sinolagomys kansuensis-Bendukidze et al.: 349, textfigs. 3, 4

2014 Sinolagomys kansuensis-Erbajeva and DaxnerHöck:234-235, text-fig. 13

Type locality: Shargaltein Tal, Gansu (China), late Oligocene Type species: Sinolagomys kansuensis Bohlin 1937

Holotype: P3-M2, Sh 429. IVPP, Beijing, China

Stratigraphic range: Late early Oligocene to early Miocene Emended diagnosis: Medium-sized, high crowned teeth with reduced roots or rootless, tooth crown is relatively straight; on upper teeth (P4, M1, M2), the depth of hypostria is variable: on P4, it extends up to half of tooth width; in M1 and M2, it is deeper; $\mathrm{p} 3$ of quadrangular shape, anterior margin of tooth smooth or with shallow depression without cement, anteroexternal fold not deep but filled with cement; trigonid of p4$\mathrm{m} 2$ is wider than talonid.

Referred material: the studied materials are represented by skull fragments, mandibles, and isolated teeth sampled from localities of Valley of Lakes, Mongolia: 
Early Oligocene (biozone B): Hsanda Gol:

SHG-AB/17-20: 1 M1 (NHMW 2013/0358/0000)

Late Oligocene (biozone C): Taatsin Gol:

TGR-C/2: 1 p3-m2 (NHMW 2013/0419/0001)

Late Oligocene (biozone $\mathrm{C} 1$ ): Toglorhoi:

TGW-A/5, TGW-A/4-5: 1 P3-M1, 1 P3, 1 P4, 1 p3-m1 (NHMW 2013/0360/0001-0004); TGS-W: 1 P4, 1 p4, $1 \mathrm{~m} 1$ (NHMW 2013/0361/0001-0003)

Tatal Gol: TAT-E/22: 1 p4 (NHMW 2016/01598/0001); TATE/27: 1 P3, 1 P4, 5 M1, 1 M2, 1 m1 (NHMW 2014/0284/00010009); TAT-E/32: 1 P3, 1 p3 (NHMW 2014/0282/0001-0002);

Loh: LOH-C/1: 1 P3 2 P4, 1 M1, $1 \mathrm{~m} 1,1 \mathrm{~m} 2$ (NHMW 2013/0362/0001-0006)

Huch Teeg: RHN-A/7: 1 P3, 1 M2, 1 p4 (NHMW 2013/0243/0001-0003); RHN-A/9: 1 P3, 3 P4, 1 M1, 2 p3, 1 p4 (NHMW 2014/0242/0001-0008); RHN-019: 1 M2, 1 p3, 1 p4, 2 m1 (NHMW 2014/0269/0001-0005)

Hotuliin Teeg: HTSE-056/1-3: 4 P3, 1 P4, 1 M1, 1 p3 (NHMW 2014/0263/0001-0007)

Early Miocene (biozone D):

Hotuliin Teeg: HTE-005: 1 P3-M2, 3 P2, 8 P3, 1 P4, 2 M1, 2 M2, 1 p3-m2, 1 p3-p4, 1 p4-m2, 1 m1-m3, 1 m1-m2, 13 p3, 1 p4, 3 m1, 3 m2, 1 m3 (NHMW 2014/0285/0001-0043); HTE008: 1 P2, 9 P3, 9 P4, 10 M1, 3 M2, 14 p4, 12 m1, 6 m2 (NHMW 2013/00156/0001-0064); HTE-014-015: 2 P2, 1 P3, 2 p4, 2 m1, 1 m2, 1 dp4 (NHMW 2014/0271/0001-0010); HTE-016-017: 4 P3, 3 P4, 3 M1, 2 M2, 3 p3, 1 p4, 3 M1, 2 M2, 1 M3, 1 dP2 (NHMW 2014/0261/0001-0023); HTE-012/7: 1 P3, 3 M1, 2 M2, 1 M2 (NHMW 2016/0158/0001-0007); HTE*: 1 p3-m3, 4 p3-m2, 2 p3-m1, 1 p3-p4, 1 p4-m3, 1 p4m2, 1 p4-m1, 1 M1-m3 (NHMW 2013/0417/0001-0028)

Huch Teeg: RHN-020: 2 P3-M2, 1 P3-M1, 1 P3, 1 P4, 1 M1, 2 M2, 1 p3, 1 p4, 2 M1 (NHMW 2013/0418/0001-0013) Description: Medium-sized ochotonid (Tables 4 and 5) with hypsodont teeth, most of the specimens rootless, but a few are rooted. Apparently the formation of roots occurs at an advanced ontogenetic stage.

P3: with moderately deep paraflexus; anteroloph short, extends to half or $1 / 3$ of tooth width; small internal hypostria filled with little cement; protocone slightly larger than hypocone

In P4-M2, depth of hypostria is variable, filled with cement; in P4, hypostria does not exceed half of tooth width, but in M1 and M2, it is deeper. The enamel band well developed on the anterior and lingual margins of tooth (Fig. 3a).

Lower jaw is relatively robust; the incisor extends posteriorly along the ventral border of the mandible to the end of $\mathrm{m} 1$. The first foramen mentale is located slightly anteriorly to $\mathrm{p} 3$ and the second below $\mathrm{m} 1$.

p3: rectangular shape; anterior border of tooth is smooth or with shallow depression, without cement; antero-external fold filled with cement; the enamel band is missing on the external and posterior borders of tooth, whereas it is quite thick along anterior and lingual margins.

In lower teeth (p4-m2), trigonid is wider than oval shaped talonid (Figs. 3b and 4a).

Discussion: Sinolagomys kansuensis from the Valley of Lakes resembles the type species from the locality Shargaltein Tal, China, by the general structure of teeth, but differs significantly by lack of roots and by slightly larger size (Tables 4 and 5). Moreover, it differs by ratio of the trigonid and talonid width in p4-m2: in Mongolian specimens, the breadth of the trigonid is slightly larger than that of the talonid in contrast to the nominative species from China in which the trigonid is much wider than the talonid. The studied sample is similar to S. kansuensis from the locality UlanTatal, China, in size, in lack of roots and general morphological structure of teeth (Huang 1987, fig. 11).

Late Oligocene to early Miocene S. kansuensis dispersed westwards over the Northern Junggar Basin, China, and reached the Aral region in Kazakhstan. In the Junggar Basin, S. kansuensis is listed in the Teersihabahe and Suosuoquan Mammal assemblages (Meng et al. 2006, 2013). In Kazakhstan, the species is mentioned by Bendukidze et al. (2009) from localities Altyn Schokysu and Akotau. The Kazakh form resembles the Mongolian sample in similar structure of teeth and size, but differs in retaining rudimentary roots.

The comparative analysis of $S$. kansuensis from the Valley of Lakes and the type material from the Shargaltein Tal, China, allows us to hypothesize that by the end of the Oligocene or beginning of the Miocene, size increased slightly, the hypostria deepened, and roots were lost completely in this Sinolagomys lineage.

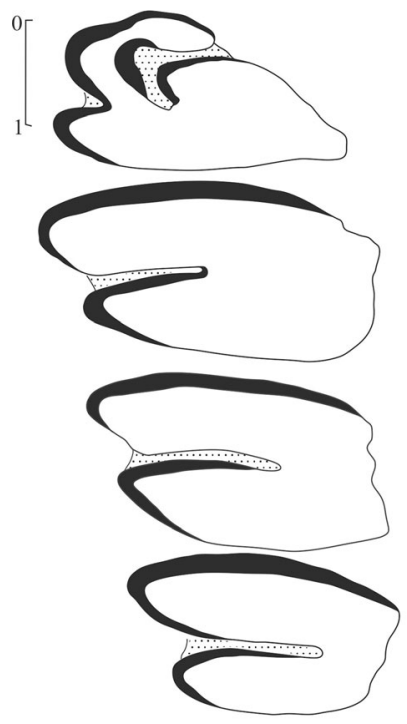

a

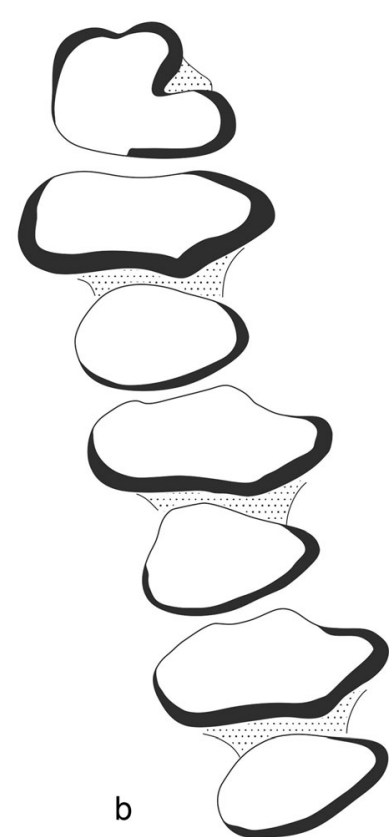

Fig. 3 Sinolagomys kansuensis Bohlin, 1937 from the Valley of Lakes in Mongolia. a Left P3-M2 (NHMW 2013/0418/0011) from Huch Teeg (RHN-020), late Oligocene (biozone C1). b Right p3-m2 (NHMW 2013/0418/0002) from Huch Teeg (RHN-020), late Oligocene (biozone C1) 


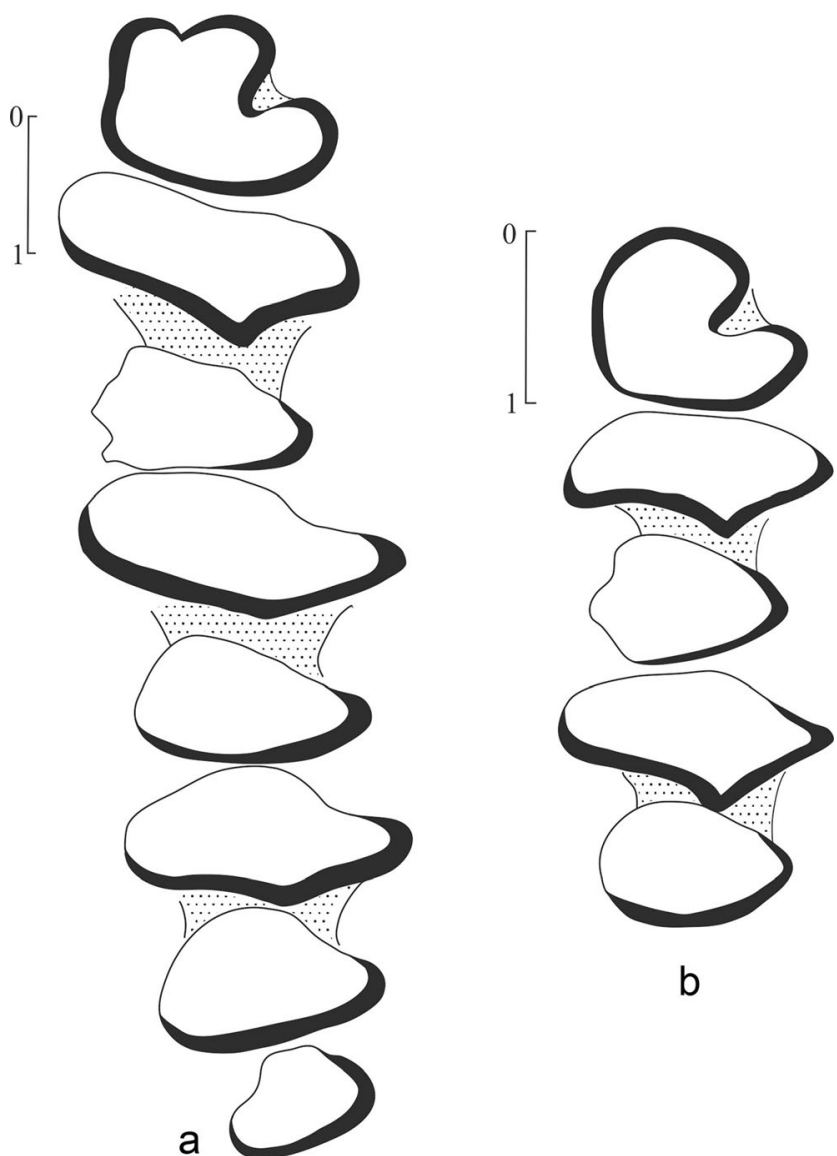

Fig. 4 Sinolagomys kansuensis Bohlin, 1937 from the Valley of Lakes in Mongolia. a Right p3-m3 (NHMW 2013/0417/0003 from Hotuliin Teeg (HTE-0), early Miocene (biozone D) Sinolagomys badamae sp.nov. from the Valley of Lakes in Mongolia. b Right p3-m1 (NHMW 2011/0191/0001) from Toglorhoi (TGW-A), late Oligocene (biozone $\mathrm{C}-\mathrm{C} 1$ )

Table 4 Upper tooth measurements (in $\mathrm{mm}$ ) of Sinolagomys kansuensis Bohlin, 1937

\begin{tabular}{lllllll}
\hline $\mathrm{Nr}$ & Specimens & $n$ & $m$ & Min & Max & $s$ \\
\hline 1 & P3 & 10 & 1.48 & 1.4 & 1.6 & 0.059 \\
2 & P3 W & 10 & 2.43 & 2.25 & 2.8 & 0.174 \\
3 & P3 W ant & 10 & 1.24 & 0.9 & 1.5 & 0.200 \\
4 & P4 & 5 & 1.48 & 1.4 & 1.55 & 0.057 \\
5 & P4 W & 5 & 2.85 & 2.55 & 3.25 & 0.276 \\
6 & P4 W hyp & 5 & 1.51 & 1.35 & 1.7 & 0.124 \\
7 & M1 & 9 & 1.44 & 1.3 & 1.6 & 0.111 \\
8 & M1 W & 9 & 2.76 & 2.3 & 3.2 & 0.347 \\
9 & M1 W hyp & 9 & 1.41 & 1 & 1.7 & 0.226 \\
10 & M2 & 2 & 1.43 & 1.35 & 1.5 & 0.106 \\
11 & M2 W & 2 & 2.55 & 2.5 & 2.6 & 0.071 \\
12 & M2 W hyp & 2 & 1.35 & 1.2 & 1.5 & 0.212 \\
\hline
\end{tabular}

Table 5 Lower tooth measurements (in mm) of Sinolagomys kansuensis Bohlin, 1937

\begin{tabular}{|c|c|c|c|c|c|c|}
\hline $\mathrm{Nr}$ & Specimens & $n$ & $m$ & Min & Max & $s$ \\
\hline 1 & p3-m3 L coronar & 5 & 8.1 & 7.8 & 8.3 & 0.200 \\
\hline 2 & $\mathrm{p} 3-\mathrm{m} 2$ & 10 & 7.3 & 7.1 & 7.8 & 0.204 \\
\hline 3 & p3-m1 & 14 & 5.38 & 5 & 6 & 0.309 \\
\hline 4 & p3-p4 & 19 & 3.32 & 3 & 3.7 & 0.212 \\
\hline 5 & $\mathrm{p} 4-\mathrm{m} 2$ & 14 & 5.7 & 3.8 & 6.5 & 0.336 \\
\hline 6 & p3 & 37 & 1.26 & 1.1 & 1.4 & 0.057 \\
\hline 7 & p3 W & 37 & 1.8 & 1.5 & 1.95 & 0.192 \\
\hline 8 & $\mathrm{p} 4$ & 35 & 1.93 & 1.6 & 2.2 & 0.157 \\
\hline 9 & $\mathrm{p} 4 \mathrm{~L} \mathrm{tr}$ & 35 & 1.21 & 0.95 & 1.6 & 0.127 \\
\hline 10 & $\mathrm{p} 4 \mathrm{~W}$ tr & 35 & 2.12 & 1.75 & 2.5 & 0.193 \\
\hline 11 & p4 L tal & 35 & 0.94 & 0.75 & 1.1 & 0.086 \\
\hline 12 & $\mathrm{p} 4 \mathrm{~W}$ tal & 35 & 1.59 & 1.25 & 1.8 & 0.131 \\
\hline 13 & $\mathrm{~m} 1$ & 28 & 2.01 & 1.55 & 2.6 & 0.211 \\
\hline 14 & $\mathrm{~m} 1 \mathrm{~L} \operatorname{tr}$ & 28 & 1.03 & 0.75 & 1.25 & 0.099 \\
\hline 15 & $\mathrm{~m} 1 \mathrm{~W}$ tr & 28 & 2.15 & 1.6 & 2.5 & 0.197 \\
\hline 16 & m1 L tal & 28 & 0.96 & 0.75 & 1.3 & 0.105 \\
\hline 17 & $\mathrm{~m} 1 \mathrm{~W}$ tal & 28 & 1.6 & 1.25 & 2 & 0.157 \\
\hline 18 & $\mathrm{~m} 2$ & 18 & 2.07 & 1.75 & 2.5 & 0.168 \\
\hline 19 & $\mathrm{~m} 2 \mathrm{~L} \mathrm{tr}$ & 18 & 2.13 & 0.91 & 2.4 & 0.355 \\
\hline 20 & $\mathrm{~m} 2 \mathrm{~W} \operatorname{tr}$ & 18 & 2.14 & 1.75 & 2.5 & 0.203 \\
\hline 21 & $\mathrm{~m} 2 \mathrm{~L}$ tal & 18 & 1.10 & 0.99 & 1.35 & 0.126 \\
\hline 22 & $\mathrm{~m} 2 \mathrm{~W}$ tal & 18 & 1.62 & 1.45 & 1.8 & 0.088 \\
\hline 23 & $\mathrm{~m} 3 \mathrm{~L}$ & 8 & 0.63 & 0.5 & 1 & 0.198 \\
\hline 24 & $\mathrm{~m} 3 \mathrm{~W}$ & 8 & 0.98 & 0.8 & 1.2 & 0.151 \\
\hline
\end{tabular}

Sinolagomys ulungurensis Tong, 1989 (Figures 5 and 6c; Tables 6 and 7)

1989 Sinolagomys ulungurensis-Tong: 103-116; text-figs. $1-10$

2014 Sinolagomys ulungurensis - Erbajeva and DaxnerHöck: 237, text-figs. 15/1-4

Type locality: North bank of the Ulungur River, Junggar basin, China, late Oligocene

Type species: Sinolagomys ulungurensis Tong, 1989

Holotype: P3-M2 (V 8264), IVPP, Beijing, China

Stratigraphic range: late Oligocene to early Miocene (biozones $\mathrm{C} 1$ to $\mathrm{D}$ )

Emended diagnosis: Small-sized; rootless, high crowned teeth; the depth of hypostria on upper teeth (P4, M1, M2) is variable, on $\mathrm{P} 4$ slightly exceeding half of tooth width, deeper in $\mathrm{M} 1$ and $\mathrm{M} 2$; $\mathrm{p} 3$ of rectangular shape, anterior margin of tooth is variable with shallow depression without cement or relatively deep depression filled with cement; antero-external fold with cement; trigonid of p4-m2 is slightly wider than talonid.

Referred material: occurrences of Sinolagomys ulungurensis in Valley of Lakes, Uvurkhangai Aimag 
Late Oligocene (biozone $\mathrm{C} 1$ ):

Tatal Gol: TAT-E/32: 1 P3, 1 P4 1 M1, 1 M2, 2 p3, 1 p4, 1 m1, 1 m2 (NHMW 2014/0283/0001-0009); TAT-E/22: 1 p3, 1 p4 (NHMW 2014/0279/0001-0002)

Del: Del-B/12: 10 P3, 2 P4, 1 M1, 1 M2, 1 m3 (NHMW 2013/0368/0001-0015)

Huch Teeg: RHN-A/9: 1 P2, 1 P3, 1 P4, 1 p3 (NHMW 2014/0244/0001-0004); RHN-020: 1 P4, 1 p4 (NHMW 2013/0375/0001-0002)

Early Miocene (biozone D):

Luugar Khudag: LOG-A/1: 2 P3, 2 P4, 3 M1, 2 p3, 1 p4, 2 m2 (NHMW 2013/0373/0001-0012)

Luuny Yas: LUS-078: 15 P3, 13 P4, 5 M1, 4 M2, 9 p3, 21 m1, 3 m2, 1 m3 (NHMW 2014/0274/0001-0072); LUS-029: 4 P3, 3 P4, 6 M1, 2 M2, 1 p3-m2, 1 p3-m1, 3 m1, 1 m2, BM (NHMW 2014/0244/0001-0022)

Del: DEL-WP-032: 1 p3-m1 (NHMW 2014/0306/0001)

Hotuliin Teeg: HTE-surface: 1 P3, 1 M1, 2 m1-m2, 2 p3, 7 p4, 4 m1, 1 m2 (NHMW 2014/0275/0001-0019); HTE-005: 6 P3, 4 P4, 7 M1, 1 p3-p4, 1 p4-m1, 1 m1-m2 1 dP2 (NHMW 2013/0374/0001 0022); HTE-008: 4 P3, 3 p3 (NHMW 2014/0374/0023-0029); HTE-012: 3 P3, 1 P4, 4 M1, 2 M2, 2 M1, 1 m2 (NHMW 2014/0374/0030-0044); HTE 016-017: 1 P3 1 M2, 2 p3, 1 p4, 1 m1, 2 m2 (NHMW 2014/0374/00450052); HTE (TGN): 2 P3-M2, 1 p3-m3, 1 p3-m2, 1 p3-p4, 1 p4-m3, 1 m1-m2, 1 p3, 2 p4, 4 m1, 1 m2 (NHMW 2014/0374/ 0053-0068); HTE-012: 5 P3, 23 m1, 4 m2, 1 p3-m2, 1 p3-p4, 7 p3, 11 p4, 5 m1, 2 m2, BM (NHMW 2014/0374/0069-0128)

Huch Teeg: RHN-012: 1 P3, 1 P4, 1 M2, 2 p3, 1 p4 (NHMW 2013/0375/0001-0006

Unkheltseg: UNCH-A/3, UNCH-A/3 + 4: 2 P2-M2, 1 P2P4, 3 P3-M2, 1 P3-M1, 1 P3-P4, 2 P4-M1, 1 dP2, 2 P2, 43 P3, 22 P4, 46 M1, 9 M2, 3 p3-m3, 3 p3-m2, 5 p3-m1, 8 p3-p4, 5 p4-m2, 2 p4-m1, 3 p4-m3, 4 m1-m3, 8 m1-m2, 2 m2-m3, 40 p3, 6 p4, 12 m1, 6 m2 (NHMW 2013/0376/0001-0212)

\section{Description}

Small-sized ochotonid (Tables 6 and 7), roots in teeth absent. P2 small, oval shape, with slight anterior groove without cement or lack of groove. As in S. major and S. kansuensis, the upper teeth (P3, P4, M1, M2) have two thin plates on the labial border (metastyle) running towards root from the occlusal surface.

Lingual borders of upper teeth (P4, M1, M2) slightly rounded; protocone and hypocone are almost equal in size; enamel band is well-developed across perimeter of tooth, but its thickness is variable - relatively thick in the anterior margin of upper teeth and posterior borders of lower teeth and thin respectively in posterior border of upper and anterior border of lower teeth.

P2: oval shape, with shallow or absent anterior groove, lacks cement (NHMW 2013/0376/0001 and NHMW 2013/0376/ 0121)
P3: with moderately deep paraflexus; anteroloph extends to mid-width of tooth; internal hypostria with little cement; protocone and hypocone of identical size; hypostria in upper teeth (P4-M2) filled with cement; depth of hypostria is variable: in P4 it reaches the middle of the tooth, and in M1 and M2 it is much deeper, may reach the external border of teeth (Fig. 5a, b).

Lower jaw relatively low, not robust; root of lower incisor extends to the talonid of $\mathrm{m} 1$; anterior foramen mentale located in front of $\mathrm{p} 3$ or below it at midlevel of mandible

p3: small, rectangular shape with rounded margins; anterior border with shallow depression without cement or with relatively deep and filled with cement. Antero-external fold with little cement. In $\mathrm{p} 4-\mathrm{m} 2$ trigonids wider than talonids, which are of oval shape (Figs. 5c-f and 6c)

m3: a small rounded, oval conid

Discussion: This small Mongolian ochotonid resembles the type series of Sinolagomys ulungurensis in general dental features and size of the teeth and undoubtedly belongs to this species. As in the type material, the Mongolian form is characterized by highly variable morphological structure of $\mathrm{p} 3$, in particular by the groove on the anterior margin of tooth which varies from shallow without cement to relatively deep and filled with cement.

S. ulungurensis is close to $S$. gracilis and S. badamae n. sp. in its small size, but it differs from them by $\mathrm{p} 3$ having a groove or depression on the anterior margin of tooth. It differs from the species S. major, S. kansuensis, S. tatalgolicus, and S. pachygnathus by its relatively smaller size, by its more complicated $\mathrm{p} 3$ with well-developed anterior grove or depression. Moreover, it differs from S. kansuensis by having rootless teeth.

Sinolagomys gracilis Bohlin, 1942 (Figures 6a, b, Table 8)

1937 Sinolagomys minor sp. nov.-Bohlin: 35, Taf. I, fig. 20, text-figs 62-65

1942 Sinolagomys gracilis n. sp.-Bohlin: Figs. 15n, ?23d, ?26f, w

Type locality: Shargaltein Tal, Gansu (China), late Oligocene Type species: Sinolagomys gracilis n. sp., Bohlin 1942

Holotype: p3-m2 sin., Sh. 434 IVPP, Beijing, China

Stratigraphic range: late Oligocene to early Miocene

Emended diagnosis: Small-sized; teeth hypsodont, rootless; p3 rectangular in shape, anterior border of tooth smooth, with extremely shallow depression, close to straight; anteroexternal fold filled with cement, in p4-m2 width of talonid approaches that of the trigonid

Referred material: A fragment of left mandible with $\mathrm{p} 3-\mathrm{m} 2$ (MPC/L-0001)—collection of the Paleontological and Geological Institute, Mongolian Academy of Sciences, Ulaanbaatar, Mongolia-was collected by Demchig Badamgarav in 2012 from LUS-29 
Fig. 5 Sinolagomys ulungurensis Tong, 1989 from the Valley of Lakes in Mongolia. a Left P3-M1 (NHMW 2013/0376/0047) from Uncheltseg (UNCH-A/3), early Miocene (biozone D). b Right P2P4 (NHMW 2013/0376/0001) from Uncheltseg (UNCH-A/3), early Miocene (biozone D). c Left p3-m1 (NHMW 2013/0376/ 0054) from Uncheltseg (UNCH$\mathrm{A} / 3$ ), early Miocene (biozone D). d Left p3-p4 (NHMW 2013/0376/ 0003) from Uncheltseg (UNCHA/3), early Miocene (biozone D). e Left p3-p4 (NHMW 2013/0376/ 0055) from Uncheltseg (UNCH$\mathrm{A} / 3$ ), early Miocene (biozone D). f Left p3-m1 (NHMW 2014/0306/ 0001) from Del (DEL-WP 032), early Miocene (biozone D)

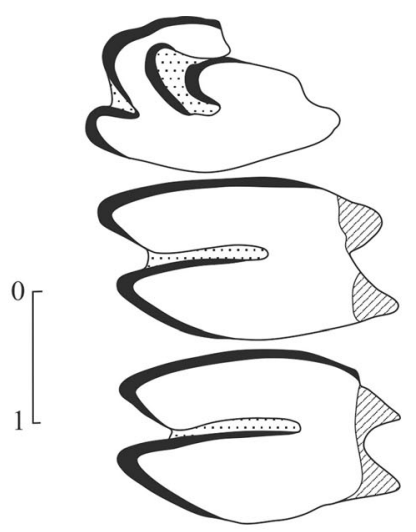

a

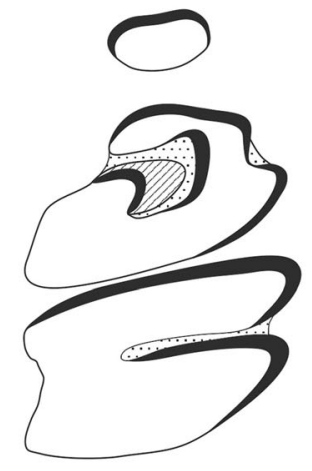

b

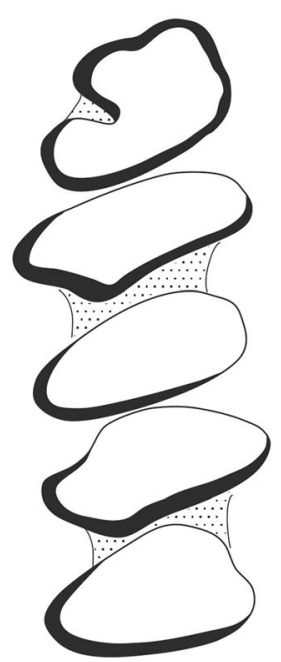

C
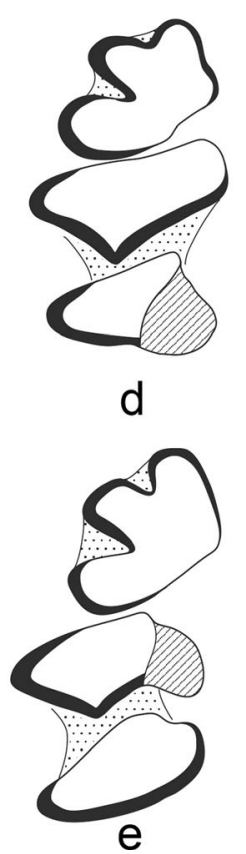

e

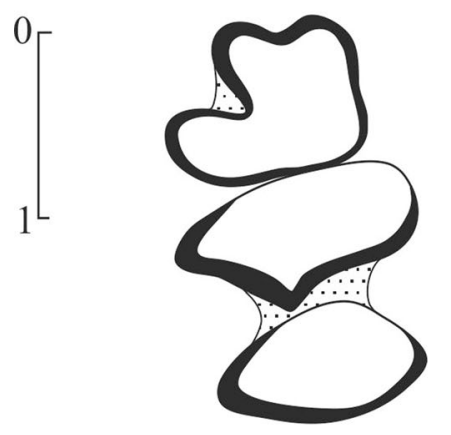

a
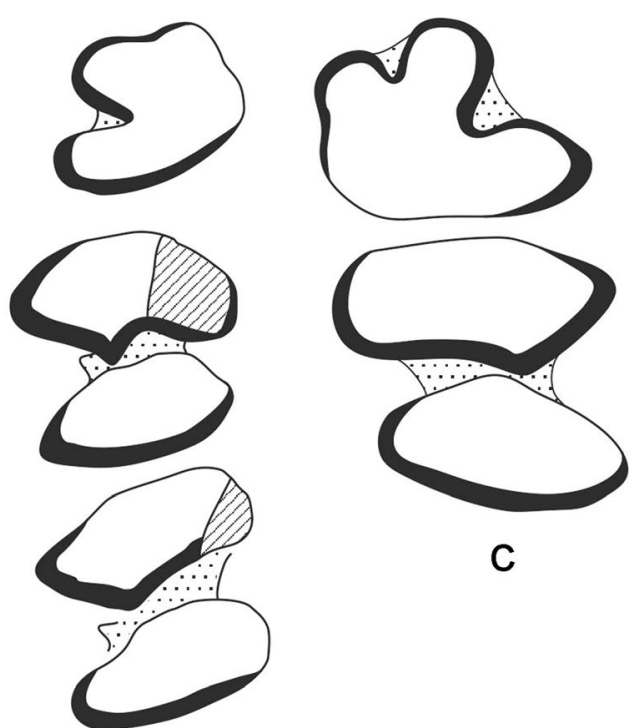

C 
Table 6 Upper tooth measurements (in $\mathrm{mm}$ ) of Sinolagomys ulungurensis Tong, 1989

\begin{tabular}{lllllll}
\hline $\mathrm{Nr}$ & Specimens & $n$ & $m$ & Min & Max & $s$ \\
\hline 1 & P3-M2 L coronar & 2 & 5.55 & 5.5 & 5.6 & 0.071 \\
2 & P3-M1 & 2 & 4.05 & 4 & 4.1 & 0.071 \\
3 & P3-P4 & 2 & 2.5 & 2.5 & 2.5 & \\
4 & P2 & 1 & 0.55 & & & \\
5 & P2 W & 1 & 0.95 & & & \\
6 & P3 & 19 & 1.22 & 1 & 1.5 & 0.135 \\
7 & P3 W & 19 & 2.19 & 1.75 & 2.6 & 0.223 \\
8 & P3 W ant & 19 & 1.07 & 0.8 & 1.35 & 0.164 \\
9 & P4 & 11 & 1.35 & 1 & 1.75 & 0.222 \\
10 & P4 W & 10 & 2.47 & 2.05 & 3.1 & 0.302 \\
11 & P4 W hyp & 11 & 1.57 & 1.05 & 2.5 & 0.361 \\
12 & M1 & 12 & 1.28 & 1.05 & 1.55 & 0.144 \\
13 & M1 W & 12 & 2.3 & 1.85 & 2.9 & 0.271 \\
14 & M1 W hyp & 12 & 1.45 & 1.1 & 1.85 & 0.233 \\
15 & M2 & 7 & 1.06 & 0.95 & 1.3 & 0.117 \\
16 & M2 W & 7 & 1.86 & 1.7 & 2.1 & 0.154 \\
17 & M2 W hyp & 7 & 1.24 & 1 & 1.55 & 0.195 \\
\hline
\end{tabular}

Locality: Luuny Jas (LUS-078 (=LUS-028/2011), P3 (right) NHMW 2016/ 0157/0001; P3 (right) NHMW 2016/0157/ 0002; Huch Teeg (RHN-A/12), P3 (right) NHMW 2016/ 0167/0001

Age: early Miocene (biozone D)

Table 7 Lower tooth measurements (in $\mathrm{mm}$ ) of Sinolagomys ulungurensis Tong, 1989

\begin{tabular}{lllllll}
\hline $\mathrm{Nr}$ & Specimens & $n$ & $m$ & Min & Max & $s$ \\
\hline 1 & p3-m2 L coronar & 3 & 5.58 & 5 & 6 & 0.520 \\
2 & p3-m1 & 5 & 3.83 & 3.45 & 4.3 & 0.390 \\
3 & p3-p4 & 6 & 2.43 & 2 & 3.2 & 0.427 \\
4 & p3 & 27 & 1.03 & 0.8 & 1.15 & 0.101 \\
5 & p3 W & 27 & 1.38 & 0.9 & 1.6 & 0.189 \\
6 & p4 & 15 & 1.65 & 1.25 & 2 & 0.246 \\
7 & p4 L tr & 15 & 0.85 & 0.65 & 1 & 0.131 \\
8 & p4 W tr & 15 & 1.75 & 1.35 & 2.2 & 0.308 \\
9 & p4 L tal & 15 & 0.79 & 0.6 & 1 & 0.113 \\
10 & p4 W tal & 15 & 1.42 & 1.1 & 1.75 & 0.202 \\
11 & m1 & 26 & 1.64 & 1.3 & 2 & 0.199 \\
12 & m1 L tr & 26 & 0.82 & 0.6 & 1.05 & 0.200 \\
13 & m1 W tr & 26 & 1.64 & 0.75 & 2.25 & 0.297 \\
14 & m1 L tal & 26 & 0.78 & 0.7 & 1.35 & 0.151 \\
15 & m1 W tal & 26 & 1.38 & 1.05 & 1.6 & 0.154 \\
16 & m2 & 9 & 1.56 & 0.8 & 2.1 & 0.350 \\
17 & m2 L tr & 9 & 0.94 & 0.7 & 1.7 & 0.313 \\
18 & m2 W tr & 9 & 1.56 & 0.75 & 2.1 & 0.369 \\
19 & m2 L tal & 9 & 0.83 & 0.7 & 1.3 & 0.187 \\
20 & m2 W tal & 8 & 1.34 & 1.1 & 1.55 & 0.145 \\
21 & m3 L & 1 & 0.55 & & & \\
22 & m3 W & 1 & 0.85 & & & \\
\hline
\end{tabular}

Description: Small-sized ochotonid, rootless, hypsodont teeth. P3 with relatively deep paraflexus; anteroloph moderately long, slightly exceeds half of tooth width; small internal hypostria with little cement; protocone slightly larger than hypocone. Metastyle small, follows from the occlusal surface downwards.

Lower jaw relatively gracile (width below p4 is $2.7 \mathrm{~mm}$ ), lower incisor extends to below the trigonid of $\mathrm{m} 2$, forming a moderate tuberosity on the lingual side of mandible. Below the tuberosity is a well-marked depression, which gradually shallows towards the ascending ramus; lateral surface of mandible smooth. Anterior foramen mentale located below p3, slightly above the ventral border of the mandible, posterior foramen under boundary of $\mathrm{p} 4$ and $\mathrm{m} 1$.

Enamel band of p3 well-developed along perimeter of tooth except at the anterior margin (Fig. 6a, b)

Fossils of S. gracilis are not numerous in Mongolian faunas as is the pattern in China.

Discussion: A small ochotonid from Shargaltein Tal, Gansu, China, was described by Bohlin in 1937 as Sinolagomys minor (type Sh 96, P3-M1) on the basis of small size in comparison to S. kansuensis and S. major. Later, Bohlin (1942) revised all small ochotonid materials from Shargaltein Tal and Taben Buluk and he discovered that the type (Sh 96) cannot be distinguished from S. kansuensis by size. Given additional materials of small forms, he erected another new small-sized species $S$. gracilis based on another specimen (left $\mathrm{p} 3-\mathrm{m} 2$, Sh 434).

He wrote (Bohlin 1942, p. 100) “...the name gracilis was substituted for "minor" as the species to which this latter name (minor) was attached was based on doubtful material". The fossils of $S$. gracilis in contrast to the other species (S. kansuensis, $S$. major), although scarce, are known from both localities Shargaltein Tal and Taben Buluk.

S. gracilis from the Valley of Lakes is close to the type material in the general structure of teeth and in having a similar ratio of the trigonid to talonid width; however, it differs from the type specimen by slightly smaller size (Fig. 6a, b; Table 8). This species differs from S. kansuensis, S. major, S. tatalgolicus, and S. pachygnathus by its much smaller size and by having talonid width practically equal to trigonid width in p4-m2. In other species, the trigonid of $\mathrm{p} 4-\mathrm{m} 2$ is much wider than the talonid.

$S$. gracilis differs from $S$. badamae sp. nov. and S. ulungurensis by slightly smaller size and from the latter by lacking a depression on the anterior border of p3. S. badamae sp. nov. differs from $S$. gracilis by having prominent, rounded anterior margin of $\mathrm{p} 3$. In addition, S. kansuensis differs from $S$. gracilis in its rooted teeth.

Sinolagomys badamae sp. nov. (Figure 4b, Table 9)

Derivatio nominis: In honor of D. Badamgarav†, Mongolian co-leader of the research team and outstanding Mongolian geologist 
Table 8 Measurements of teeth (in mm) of Sinolagomys gracilis (Bohlin 1942)

\begin{tabular}{|c|c|c|c|c|c|c|c|c|c|c|}
\hline & p3-m2 & p3-m1 & p3-p4 & p3 L & p3 W & $\mathrm{p} 4 \mathrm{~L}$ & p4 Wtr & p4 Wtal & P3 L & P3W \\
\hline Type Sh 434 & 6.3 & 4.8 & 3.15 & 1 & 1.35 & 1.5 & 1.5 & 1.35 & & \\
\hline MPC/L-0001 (LUS-29) & 4.75 & 3.35 & 2 & 0.8 & 1 & 1.35 & 1.25 & 1.15 & & \\
\hline LUS-078 & & & & & & & & & $1.0 ; 1.0$ & $1.75 ; 1.8$ \\
\hline RHN-A/12 & & & & & & & & & 1.0 & 1.5 \\
\hline
\end{tabular}

Type locality: Toglorhoi, Uvurkhangai, Valley of Lakes, Mongolia; sample TGW-A* (asterisk indicates collection from surface along section TGW-A); red-brown silty clay of the Hsanda Gol Fm.; late Oligocene, Biozone C-C1

Type species: Sinolagomys badamae sp. nov.

Holotype: p3-m1 (right)_NHMW 2011/0191/0001, Natural History Museum, Vienna, Austria

Age: Late Oligocene

Paratypes: P3 (right) NHMW 2011/0191/0002; p3-p4 (right) NHMW 2011/0191/0003; p4 (left) NHMW 2011/0191/0004; m1 (right) NHMW 2011/0191/0005

Diagnosis: Small-sized rootless ochotonid with hypsodont teeth; anterior margin of p3 prominent (convex), rounded; trigonid in $\mathrm{p} 4-\mathrm{m} 1$ much wider than talonid.

Differential diagnosis: Sinolagomys badamae sp. nov. differs:

- From the largest species $S$. major, by much smaller size and prominent $\mathrm{p} 3$

- From S. kansuensis by smaller size and prominent p3, lack of roots in $S$. badamae

- From S. pachygnathus by prominent p3, smaller size and by the much wider trigonid than talonid in S. badamae

- $\quad$ From $S$. gracilis by slightly larger size, by greater breadth of trigonid relative to talonid (width of talonid in $S$. gracilis approaches that of the trigonid)

- From S. ulungurensis by lack of depression on the anterior margin of $\mathrm{p} 3$, by much wider trigonid than talonid (trigonid only slightly wider in S. ulungurensis)

- From $S$ tatalgolicus by lack of deep depression on the anterior margin of p3 and smaller size

Description

Small-sized ochotonid (Table 9)

Table 9 Measurements of teeth (mm) of Sinolagomys badamae sp. nov

\begin{tabular}{|c|c|c|c|c|c|c|}
\hline & p3-m1 & p3-p4 & p3 & $\mathrm{p} 4$ & $\mathrm{~m} 1$ & P3 \\
\hline$L$ & 4.0 & $2.5 ; 3.0$ & $1.0 ; 1.18$ & $1.5 ; 1.7 ; 1.7$ & $1.5 ; 1.75$ & 1.4 \\
\hline$W$ & & & $1.2 ; 1.4$ & & & 2.3 \\
\hline Wtr & & & & $1.55 ; 1.75 ; 1.8$ & $1.6 ; 1.8$ & \\
\hline Wtal & & & & $1.15 ; 1.35 ; 1.4$ & $1.1 ; 1.45$ & \\
\hline
\end{tabular}

P3: rootless, oval-trapezoidal outline, its anterior width relatively less than posterior width; paraflexus moderately deep; anteroloph extends to $1 / 3$ of tooth width; internal hypostria short, with little cement. Along external border of the tooth, thin plate follows from the occlusal surface towards root.

Mandible relatively high and robust (depth below p4 5.0$5.2 \mathrm{~mm}$; width, 3.2-3.3 $\mathrm{mm}$ ); the base of lower jaw is wide; the lower incisor extends to the talonid of $\mathrm{m} 1$ forming marked tuberosity on both lateral and medial surfaces of mandible. Anterior foramen mentale located anterior to $\mathrm{p} 3$ at mid-level of mandible. The thickness of enamel band in lower teeth (p3$\mathrm{m} 1)$ varies: it is well developed along the perimeter of teeth, except for the anterior margin of trigonid and lingual part of talonid.

p3: rectangular shape with rounded borders; anterior margin of tooth prominent, lingual and posterior margins are practically straight; anteroconid elongated; enamel band is well developed on all borders of tooth; antero-external fold of tooth is relatively shallow, with little cement.

p4-m1: trigonid significantly wider than talonid; in the holotype, both labial and lingual edges of trigonid in $\mathrm{p} 4$ and $\mathrm{m} 1$ are relatively sharpened to acute angles, but in the paratype, they are slightly rounded; in all specimens, the posterior margin of the trigonid has a short sharp projection and the structure of the talonid is the same; talonid is oval or egg-shaped, with rounded lingual and sharp labial edges, enamel band well developed along posterior border of talonids.

Discussion: Sinolagomys badamae sp. nov. differs from all other species of the genus by the morphological structures of teeth and size as noted above. The species is characterized by advanced features such as lack of roots and the peculiar, prominent anterior portion of p3; however, some archaic characters are retained as well. Archaic features are much wider trigonid than talonid, lower incisor extending far posteriorly (to the talonid of $\mathrm{ml}$ ), and mandible relatively robust despite the small size.

\section{Conclusion}

Fossils of Sinolagomys are rather well-preserved across the Oligocene to Miocene informal biozones $\mathrm{C} 1-\mathrm{D}$ of the Valley of Lakes in Central Mongolia. First very rare occurrences are evidenced in biozone $\mathrm{B}$ (two specimens) and in 
biozone $\mathrm{C}$ (one specimen), but the main distribution of the genus was during the biozones $\mathrm{C} 1, \mathrm{C} 1-\mathrm{D}$, and $\mathrm{D}$. The comprehensive analysis of the entire collection shows that several Oligocene species were distributed from the northern part of China to Central Mongolia and Eastern Kazakhstan. The diversity and abundance of Sinolagomyinae is highest in Biozone $\mathrm{C} 1$, and they appear to be an endemic taxon of Central Asia.

The Neogene record of Sinolagomys in Central Asia continues in the early Miocene with the appearance of S. ulungurensis alongside the Oligocene species $S$. major and S. kansuensis.

No significant morphological changes in tooth structure of S. major and S. kansuensis from the Valley of Lakes sites are observed during the early late Oligocene and Miocene. Possibly, these species were rather conservative forms that persisted on landscapes under environments that did not change greatly.

The fossil history of the Ochotonidae offers clues to the palaeoclimate of the mid-Cenozoic world, especially for the palaeoecology of eastern Asia. The diversity patterns observed among fossil representatives indicate the changing conditions of dominant climatic patterns. Heightened fossil diversity is slowly emerging and indicates an increasing component of open habitat in a mosaic of grasslands and woodlands during the middle Cenozoic in Asia. This led to the development of the main ochotonid adaptive type. Inhabiting open landscapes and taking grass as nourishment, sinolagomyins are distinguished by increasing hypsodonty of the teeth at the early stage of their evolutionary development. Well-developed roots were lost as crown height increased, and root closure occurred late in ontogeny, yielding "rudimentary roots" (closed pulp cavities at the base of teeth). Later, "rudimentary roots" were lost completely as the teeth became fully hypsodont with open pulp cavities.

Erbajeva et al. (2015) summarized much of the known record of Neogene and late Paleogene ochotonids, especially Asian records. There are additional important records of early Ochotoninae, such as early Miocene Alloptox (Mizuhoptox) from Japan (Tomida 2012). Apparently, the Neogene was the time of diversification and increasing abundance of advanced ochotonids. Oligocene Sinolagomyinae, rather than Ochotoninae, characterized late Paleogene assemblages of Asia. Now it is clearer that Sinolagomyinae were actually rather abundant in the late Oligocene and early Miocene of Asia. A hypothetical scenario for ochotonid evolution may be proposed.

A long, sustained period of global cooling characterized the late Eocene, leading to climatic oscillations during the Oligocene Epoch ("Zoogeography of Paleogene Asia" 1974; Berggren and Prothero 1992; Zachos et al. 2001). Until the late Oligocene, early ochotonids were uncommon elements in terrestrial communities. With global cooling and growing seasonality of precipitation, habitats changed, becoming more open, and primitive ochotonids of the subfamily Sinolagomyinae flourished. Locally they became common, as in the Valley of Lakes, Mongolia (Tab. 1). The genus Sinolagomys is the earliest species-rich form of the subfamily, and it flourished during the late Oligocene and early Miocene. We hypothesize Sinolagomys as a characteristic element of small mammal assemblages of eastern Asia in which subtropical forests had been replaced by landscapes with open woodlands and xerophytic vegetation.

Acknowledgements Open access funding provided by Austrian Science Fund (FWF). We thank all members of the AustrianMongolian project for their contributions in collecting fossils during the field work. Many thanks to Göhlich U., Harzhauser M. (NHMW) for fruitful discussions. M. Erbajeva is grateful to Li CH., Zheng Sh., Zhang Z., Li Q. (IVPP), Tedford R.†, Marcus L. † (AMNH), and Lopatin A. (PIN RAN) for the opportunity to study sinolagomyin collections under their care. We want to thank Jérôme Prieto and an anonymous reviewer for their valuable and helpful comments. This research was supported by the projects of the Austrian Science Fund (FWF): P-10505-GEO, P-15724-N06, and P-23061-N19.

Open Access This article is distributed under the terms of the Creative Commons Attribution 4.0 International License (http:// creativecommons.org/licenses/by/4.0/), which permits unrestricted use, distribution, and reproduction in any medium, provided you give appropriate credit to the original author(s) and the source, provide a link to the Creative Commons license, and indicate if changes were made.

\section{References}

Asher, R. J., Meng, J., Wible, J. R., McKenna, M. C., Rougier, G. W., Dashzeveg, D., \& Novacek, M. J. (2005). Stem Lagomorpha and the antiquity of Glires. Science, 307, 1091-1094.

Bendukidze, O. G., De Bruijn, H., \& Van Den Hoeck-Ostende, L. (2009). A revision of Late Oligocene associations of small mammals from the Aral Formation (Kazakhstan) in the National Museum of Georgia, Tbilisi. Palaeodiversity, 2, 343-377.

Berggren, W. A., \& Prothero, D. R. (1992). Eocene-Oligocene climate and biotic evolution. Princeton: Princeton University Press.

Bohlin, B. (1937). Oberoligozäne Säugetiere aus dem Shargaltein-Tal (Western Kansu). Palaeontologia Sinica New Sesies C, 3, 1-66.

Bohlin, B. (1942). The fossil mammals from the Tertiary deposit of Taben-buluk, Western Kansu. Part I. Insectivora and Lagomorpha. VI. Vertebrate Palaeontology, 3, 1-113.

Daxner-Höck, G., Badamgarav, D., Barsbold, R., Bayarmaa, B., Erbajeva, M., Göhlich, U. B., Harzhauser, M., Höck, E., Höck, V., Ichinnorov, N., Khand, Y., Lopez-Guerrero, P., Maridet, O., Neubauer, T., Oliver, A., Piller, W. E., Tsogtbaatar, K., \& Ziegler, R. (2017). Oligocene stratigraphy across the Eocene and Miocene boundaries in the Valley of Lakes (Mongolia). In G. Daxner-Höck and U. Göhlich (Eds.) The Valley of Lakes in Mongolia, a key area of Cenozoic mammal evolution and stratigraphy. Palaeobiodiversity and Palaeoenvironments, 97(1). doi:10.1007/s12549-016-0257-9 (this issue).

De Muizon, C. (1977). Revision des lagomorphes des couches a Baluchitherium (Oligocene superieur) de San-tao-ho (Ordos, 
Chine). Bulletin de Museum National d'Histoire Naturelle Section Science de la Terrre, 65, 265-294.

Erbajeva, M. A. (1988). Cenozoic pikas (Taxonomy, Systematics and Phylogeny). Moscow: Nauka [in Russian].

Erbajeva, M. A. (1994). Stratigraphical distribution of Lagomorpha (Mammalia) in tertiary deposits of Zaissan depression (Eastern Kazakhstan). In Y. Sokolov (Ed.), Paleotheriology (pp. 65-78). Moscow: Nauka Press [in Russian].

Erbajeva, M. A. (2007). 5. Lagomorpha (Mammalia): preliminary results. In Daxner-Höck, G. (Ed.), Oligocene-Miocene vertebrates from the Valley of Lakes (Central Mongolia): morphology, phylogenetic and stratigraphic implications. Annalen des Naturhistorischen Museums Wien, Serie A, 108, 165-171.

Erbajeva, M. A., \& Daxner-Höck, G. (2014). The most prominent Lagomorpha from the Oligocene and Early Miocene of Mongolia. Annalen des Naturhistorischen Museums Wien, Serie A, 116, 215-245.

Erbajeva, M. A., Flynn, L. J., \& Alexeeva, N. (2015). Late Cenozoic Asian Ochotonidae: taxonomic diversity, chronological distribution and biostratigraphy. Quaternary International, 355, 18-23.

Erbajeva, M. A., Angelone, C., \& Alexeeva, N. (2016). A new species of the genus Amphilagus (Lagomorpha, Mammalia) from the Middle Miocene of south-eastern Siberia. Historical Biology, 28(1-2), 199-207.

Gradstein, F. M., Schmitz, M. D., \& Ogg, G. M. (2012). The geologic time scale 2012. 2 vols. Oxford: Elsevier.

Gureev, A. A. (1960). Oligocene lagomorphs (Lagomorpha) from Mongolia and Kazakhstan. In K. K. Flerov (Ed.), Tertiary Mammals (pp. 5-34). Paleontological Institute, Transactions, Moscow, Nauka Press, 77(4). [in Russian].

Gureev, A. A. (1964). Fauna of the USSR, Mammals, Lagomorphs (Lagomorpha, Mammalia) Vol. 1, issue 10, Moscow-Leningrad, Nauka Press [in Russian].

Höck, V., Daxner-Höck, G., Schmid, H. P., Badamgarav, D., Frank, W., Furtmüller, G., Montag, O., Barsbold, R., Khand, Y., \& Sodov, J. (1999). Oligocene-Miocene sediments, fossils and basalts from the Valley of Lakes (Central Mongolia) - an integrated study. Mitteilungen der Geologischen Gesellschaft Wien, 90, 83-125.

Huang, X. (1987). Fossil ochotonids from the middle Oligocene of Ulantatal, Nei Mongol. Vertebrata PalAsiatica, 25(4), 260-282 [in Chinese with English summary].

Li, C., \& Qiu, Z. (1980). Early Miocene mammalian fossils of Xining Basin, Qinghai. Vertebrata PalAsiatica, 18(3), 198214 [in Chinese].

Lopatin, A. (1998). A revision of the early Miocene Lagomorpha (Mammalia) from the North Aral region. Paleontological Journal, 32, 291-304.

Lopez Martinez, N. (1989). Revision sistematica y biostratigraphica de los Lagomorpha (Mammalia) del Terciario y Cuaternario de España.
Memorias del Museo Paleontologico de la Universidad de Zaragoza, 3, 1-350.

Luterbacher, H. P., Ali, R. J., Brinkhuis, H., et al. (2004). The paleogene period. In F. M. Gradstein, J. G. Ogg, \& A. Smith (Eds.), A geologic time scale 2004 (pp. 384-408). Cambridge: Cambridge University Press.

Matthew, W., \& Granger, W. (1923). New nine rodents from the Oligocene of Mongolia. American Museum Novitates, 102, 1-10.

Meng, J., Ye, J., Wu, W.-Y., Yue, L., \& Ni, X. J. (2006). A recommended boundary stratotype section for Xiejian stage from Northern Junggar Basin: implications to related biochronostratigraphy and environmental changes. Vertebrata PalAsiatica, 44(3), 205-236 [in Chinese with English summary].

Meng, J., Ye, J., Wu, W.-Y., Ni, X. J., \& Bi, S.-D. (2013). A single-point base definition of the Xiejian age as an exemplar for refining Chinese land mammal ages. In X.-M. Wang, L. J. Flynn, \& M. Fortelius (Eds.), Fossil mammals of Asia: Neogene biostratigraphy and chronology (pp. 124-141). New York: Columbia University Press.

Steininger, F. F. (1999). The Continental European Miocene. Chronostratigraphy, geochronology and biochronology of the miocene "European Land Mammal Mega-Zones" (ELMMZ) and the Miocene "Mammal-Zones (MN-Zones)". In G. E. Rössner \& K. Heissig (Eds.), The Miocene land mammals of Europe (pp. 9-38). München: Verlag Dr. Friedrich Pfeil.

Teilhard de Chardin, P. (1926). Description des mammiferes tertiaries de Chine et de Mongolie. Annales de Paleontologie, 15, 1-52.

Tomida, Y. (2012). New species of Alloptox (Lagomorpha, Ochotonidae), first record of the genus in Japan, and subgeneric distinction. Paleontological Research, 16, 19-25.

Tong, Y. S. (1989). A new species of Sinolagomys (Lagomorpha, Ochotonidae) from Xinjiang. Vertebrata PalAsiatica, 27(2), 103 116 [in Chinese with English summary].

Wang, B. Y., \& Qiu, Z. X. (2000). Micromammal fossils from red mudstone of lower member of Xianshuihe Formation in Lanzhou basin, China. Vertebrata PalAsiatica, 38(4), 255-273 [in Chinese with English summary].

Wolfe, J. A. (1971). Tertiary climatic fluctuations and methods of analysis of Tertiary floras. Palaeogeography, Palaeoclimatology, Palaeoecology, 9, 27-57.

Zachos, J., Pagani, M., Sloan, L., Thomas, E., \& Billups, K. (2001). Trends, rhythms, and aberrations in global climate 65 Ma to present. Nature, 292, 686-693.

Zoogeography of Paleogene Asia. (1974). Transactions of the Paleontological institute RAS, 146, Moscow, Nauka Press [in Russian]. 